\title{
Oil Painting Art Appreciation Platform Based on Mobile Information System
}

\author{
Jing Zhang \\ Academy of Fine Arts, Hulunbeier University, Hulunbeier 021008, Inner Mongolia, China \\ Correspondence should be addressed to Jing Zhang; zhangjing@hlbec.edu.cn
}

Received 12 October 2021; Revised 26 December 2021; Accepted 12 January 2022; Published 25 February 2022

Academic Editor: Deepak Kumar Jain

Copyright ( 2022 Jing Zhang. This is an open access article distributed under the Creative Commons Attribution License, which permits unrestricted use, distribution, and reproduction in any medium, provided the original work is properly cited.

\begin{abstract}
Art is the product of culture, and the collision of cross-cultural communication and Chinese and Western culture has promoted the development and innovation of art. Today, oil painting is well known as a kind of art. At first, oil painting did not exist as art. It came from the most primitive activities of mankind and gradually became one of the categories of art with the development of civilization. In the context of the rapid development of material civilization today, the huge benefits brought by science and technology have promoted people's pursuit of practicability. Oil painting has been used more as an instrument and has largely lost its purity as an art. Sexuality and spirituality and traditional cultural communication methods limit the development and inheritance of oil painting art. Oil painting can decorate the interior space and increase the income of museum tickets; it has collections that can add value; it cultivates readers' temperament; the author expresses his emotions. Based on that, this article is based on the research of mobile information system and oil painting art cultural appreciation platform. The gradient descent method is the earliest, simplest, and most commonly used optimization method. The convergence speed of the gradient descent method in the region close to the optimal solution is significantly slower, and the use of the gradient descent method to solve the problem requires many iterations. First of all, this article uses the method of literature data to study the theories of keywords such as oil painting art and cultural communication. Then, oil painting art and culture communication model is designed through the classification algorithm under mobile information network. Finally, it analyzes the status quo of art culture dissemination and the dissemination of oil painting art culture in my country. Taking figure painting and landscape painting as examples, their total added values accounted for $33.4 \%$ and $49.2 \%$, respectively. This shows that the overall scale of my country's oil painting industry has been expanding year by year, and its status in the national economy has also been steadily improved.
\end{abstract}

\section{Introduction}

Oil painting art cultural dissemination and digital inheritance significance are established on the basis of its rich artistic, historical value and dazzling national culture. Oil painting art resources not only condense the history, culture, and skills of oil painting development but also contain national traditional culture, national spirit, and aesthetic appeal. With the increasing frequency of cultural exchanges in various regions of modern society, the cross-cultural spread and inheritance of oil painting art are also facing new opportunities and challenges. Oil paintings are kept for a long time. Poor preservation will make them darken, turn yellow, crack, embrittle, chalk, and so forth. These characteristics will limit the spread of oil paintings. In addition, cultural differences and recognition will form certain obstacles to the optimization of spread.

The complex background of multiculturalism, the rapid development of information technology, and the integration and protection of globalization and local culture have made the cultural inheritance and development of oil painting art a hot topic of concern to society and scholars, and the spread of oil painting art is under the same era background, becoming one of the hot issues to be solved urgently. The artistry of oil painting lies in its diverse graphic expressions and superb techniques. All kinds of oil painting styles can maintain thousands of years of tradition, and they are formed by the people's wisdom and sweat. Transparent overcoloring method, that is, multilevel drawing, is done with pigments that are not added with white but are only 
diluted by toner. The next layer must be colored after each layer is dry. Since the color of each layer is thinner, the color of the lower layer can be faintly revealed, forming a subtle hue that changes with the color of the upper layer. Opaque overcoloring method is also known as multilevel coloring method. When painting, first a single color is used to draw the outline of the body, and then colors are used to shape it in multiple layers. The dark parts are often painted thinner, and the middle tones and bright parts are painted thickly, or covered or left, to form a contrast of color blocks.

Sikorski JJ mainly discussed the fourth industrial revolution and gave examples of application markets that promote the interaction between machines and build M2M power. The proposed scenario involves two power producers and one power consumer trading. All participants are provided with real data generated by the flow chart model. This work helps to achieve a proof of concept for this scenario. The conclusion is that this technology may have major research flaws to support and improve the efficiency of the revolution and to determine future research fields [1]. Gao's cross-cultural communication has become an indispensable part of today's world, especially in developed countries with large immigrant populations. The healthcare system is one of the important fields. In this field, medical staff and patients may have different cultures, so it is necessary to have effective communication between culturally different patients and medical staff. However, cross-cultural communication is affected by psychological factors related to culture and way of thinking. Adaptation orientation is one of the important factors, and people with different orientations interact with people with different cultural backgrounds in different ways. Another important factor of cultural orientation is that different fields define the characteristics of different cultures. In addition, the tendency to use native or nonnative speakers among culturally different patients is a key factor in establishing a good relationship between patients and healthcare practitioners. His research is mainly about the application of cultural exchange characteristics in health care, but he has not conducted relevant experiments, nor has he conducted relevant survey information such as questionnaire surveys [2]. Hotsaliuk A explored the peculiarities of the development of oil painting art in Ukraine (from the end of the 20th century to the beginning of the 21st century). What is certain is that the development of modern Ukrainian oil painting art is characterized by genre diversity and the positive expression of neotraditionalism with new social and cultural phenomena and processes. The practice of modern art proves that domestic sculptors are highly specialized and they are creatively integrated into the process of European and world culture and art on a regular basis. As people became more and more interested in folk literature and art, ancient Eastern religions, and various national cultures, artists' fascination with the subconscious began to emerge. Neoclassical sculptors are actively turning to the artistic language of ancient oil painting images. The conclusion is that, in the late 20th century-early 21st century, the work of sculptors in various regions of Ukraine is constantly being strengthened, and the organization of the art center is also continuing. The tradition began in 1999 and was organized by the National Union of Artists of Ukraine, aiming to hold an exhibition across Ukraine. His research shows that oil painting art is indeed continuously enhanced and developed, but he did not explain how to carry out the spread of oil painting culture and the specific development form [3]. Sculpture is a three-dimensional art, while painting is a two-dimensional art, which is limited to graphic art. Sculpture is more difficult than painting. It needs a strong sense of space and threedimensionality. Oil painting emphasizes the beauty of richness, dignity, and harmony in color. Printmaking pays attention to "knife flavor," "wood flavor," the beauty of printing, and so forth. Watercolor painting pays attention to the bright, clear, and rich artistic beauty formed by water, color, and brushwork.

This article studies the spread of oil painting art culture. From the perspective of the lack of form of oil painting art cultural communication, a form of communication is proposed to make the industrial chain of oil painting art cultural communication transparent and enhance its authenticity. At the same time, the scope of the spread of oil painting art and culture has been expanded to better promote cultural exchanges.

\section{Research Method Based on Mobile Information System and Oil Painting Art Appreciation Platform}

2.1. Oil Painting Art. Speaking of art, our many prose and poetry works in life, our paintings, drawings, and oil paintings, our music, dances, and performances, and so forth are quite obvious and are often created for entertainment purposes, but they all seem to be called art. There is a difference $[4,5]$; we must be clear about the relationship between entertainment and art; otherwise, we will compare the real art and entertainment, making them have an equivalent relationship, thus destroying the concept of art itself $[6,7]$. Art is creation. It brings things to people, allowing viewers to generate new ideas and experience new experiences; entertainment is a form of consumption, the past is gone, and nothing can be left behind. If the purpose of an oil painting artist's head is to make the face, demeanor, and temperament lifelike and to impress and attract people, then it cannot be called art anyway. This is a skill, which is no different from people praising superb technology $[8,9]$.

First of all, we must know that the "art" and "world" discussed here are all constructed by humans, and people need to grasp this constructed "world" through concepts $[10,11]$. Transparent vegetable oil is used with paint materials. Hard materials create a visual and tangible art image with a certain space to reflect social life and express the artist's aesthetic feelings, aesthetic emotions, and aesthetic ideals. Oil painting is the one that has such conditions. As universally valid knowledge, this is the definition of oil painting itself. We can further elaborate on the stipulation of oil painting. The stipulation is divided into attributes and relationships. The oil painting itself is two-dimensional, material, expressive, and so forth. These are the visible and invisible attributes $[12,13]$; the 
oil painting is in the exhibition in the museum; oil painting is one of the art categories. Oil painting and other paintings coexist; we can infer oil painting and non-oil painting from their essential attributes $[14,15]$. This is the first "What is oil painting?"; but it is not enough to know the attributes of oil painting. To know the true face of Mount $\mathrm{Lu}$, you must also look at Mount Lu from the outside. Continue to question the relationship and look at oil painting from multiple angles. This is the second "What is oil painting?" $[16,17]$.

When we cannot view an oil painting from an aesthetic point of view, it is a piece of material, an object. An oil painting placed on a booth is no different from a cup placed on a tea table. People carry the oil painting to the gallery for display $[18,19]$, as if a tea set is placed on display in a shopping mall. Oil paintings are paid for collection, just like tea sets are sold for a good price. Including all objects such as oil paintings and tea cups, they all have a material element, and people's understanding of oil painting cannot get rid of the material element of the work [20, 21]. There are stone objects in the architecture and wood objects in the woodcarving works; there are paper things in oil paintings. In the work, the material factor is so stable. It is self-evident that the oil painting exists in the material, but the oil painting is something other than the material factor [22]. It is true that an oil painting is a manufactured object, but it also expresses something else, practical, nonpractical, beautiful, and a certain pure meaning. We have to understand oil painting in different dimensions in order to have a comprehensive understanding of oil painting and to appreciate the existence of oil painting as a "meaning" $[23,24]$.

2.2. Cultural Dissemination. Cultural dissemination can also be called "cultural diffusion." Cultural diffusion refers to both a process of flow and a process of dissemination. The process of flow refers to the dissemination of people's cultural background, values, cognition, and behavior patterns within a certain range in the form of ideology or form. This kind of dissemination is a process in which culture spreads and walks from its place of origin or social groups in the region to other regions or social groups in other regions [25]. According to the sequence of time and the pace of social development, cultural communication can be divided into five stages. The first stage is oral communication, the second is written communication, the third is printing communication, the fourth is the electronic communication stage, and the fifth is the network communication stage. Oral communication is the most commonly used form of communication in daily life; the ability of written communication is mainly manifested in the flexible use of words and sentences, the implementation of grammatical structure, the accurate grasp of format, and so forth. The influence of the rules is established within a specific group on written communication; restrictions are large; network communication greatly reduces the cost of communication and improves the efficiency of communication; the timeliness of communication and the requirements of equality are realized; with the support of firewall technology, it improves the sense of security of instant information. In the five stages, the communication content covered includes material, spiritual, media, image, sports, food and clothing, and tourism culture. The cultural dissemination of the Internet can create a new educational method and change the moral education system of young people. At the same time, it is conducive to the dissemination and inheritance of excellent traditional culture, and it is a booster of globalization. The media and cultural communication in the above content can be divided into four types: the first is newspapers, the second is the Internet, the third is broadcasting, and the last is film and television cultural communication; the specific communication methods can be divided into mass communication and interpersonal communication. In addition, cultural communication can be divided into two types in terms of expression. The first cultural communication system is centered on phonetic symbols, and the second cultural communication system is centered on visual symbols.

For culture to spread, it needs the existence of media. These media are called communication media or media for short. These media are all playing a vital role in the process of cultural dissemination with their unique advantages. Traditional media use the promotion and popularization of print media as a sign to convey information to the audience. However, there are many types of media in the $21 \mathrm{st}$ century, which is the mass media that everyone usually hears. Besides traditional newspapers and magazines, there are modern developed radio and television, network digital media and so on.

\section{Research Experiment Based on Mobile Information System and Oil Painting Art Appreciation Platform}

3.1. Oil Painting Art Culture Communication Model. The dissemination of oil painting art and culture is not limited to the traditional way of dissemination. With the help of modern technology, oil painting culture can spread to all corners of the world faster and more conveniently.

3.1.1. Logistic Regression Algorithm. The logistic regression algorithm is actually the simplest algorithm in the neural network, which involves the loss function, which can also be called the log-likelihood function, and the larger the value of this function, the better.

$$
\begin{aligned}
o & =\sigma(\text { net })=\frac{1}{1+e^{- \text {net }},} \\
f(x) & =\operatorname{sigmoid}\left(x^{T} y+a\right),
\end{aligned}
$$

where $x$ and $y$ represent constants and $o$ represents function values. Now combine the linear function with the sigmoid function. Replace $x$ with $\theta^{T} x$ to get the model algorithm function:

$$
l_{\theta}(x)=h\left(\theta^{T} x\right)=\frac{1}{1+e^{-\theta^{T} x}} .
$$

In the entire compound function, sigmoid is a fixed function with no parameters. So $\theta$ is the only parameter. 
Our purpose of constructing the loss function is that we need to have a standard under which to find the best model that can best fit the training samples.

(1) The strategy function is

$$
\left(p_{\theta}\left(x_{i}\right)\right)^{y_{i}}\left(1-p_{\theta}\left(x_{i}\right)\right)^{1-y_{i}} \text {. }
$$

The larger the value is, the better the model fits the sample.

(2) Consider the impact of the sample on the model:

$$
\prod_{i=1}^{m}\left(p_{\theta}\left(x_{i}\right)\right)^{y_{i}}\left(1-p_{\theta}\left(x_{i}\right)\right)^{1-y_{i}} \text {. }
$$

(3) Construct the loss function of the logistic regression classifier:

$$
T(\theta)=\prod_{i=1}^{m}\left(p_{\theta}\left(x_{i}\right)\right)^{y_{i}}\left(1-p_{\theta}\left(x_{i}\right)\right)^{1-y_{i}} .
$$

If a certain value of the harness happens to make the loss function reach the maximum, then the model corresponding to this value is the best model.

The Korean style of the loss of the logistic regression classifier is to find the maximum value, and it is different to find the minimum value by the general loss function. In practice, the logarithm of the pair $T(\theta)$ is often taken:

$$
l(\theta)=\log T(\theta)=\sum_{i=1}^{m}\left(y_{i} \log P_{\theta}\left(x_{i}\right)+\left(1-y_{i}\right) \log \left(1-P_{\theta}\left(x_{i}\right)\right)\right) .
$$

After taking the logarithm, we call it the log-likelihood function.

Derivation of the above formula is

$$
\frac{\partial T(\theta)}{\partial \theta}=\sum_{i=1}^{n} y_{i} x_{i}-\sum_{i}^{n} \frac{e^{\theta^{T} x_{i}}}{1+e^{\theta^{T} x_{i}}} x_{i}=\sum_{i=1}^{n}\left(y_{i}-\sigma\left(\theta^{T} x_{i}\right)\right) x_{i}
$$

Iteration weight is

$$
\theta_{j}=\theta_{j}+\beta \sum_{i=1}^{m}\left(y_{i}-p_{\theta}\left(x^{(i)}\right)\right) x^{(i)}
$$

The iterative process is not necessarily convergent.

3.1.2. Evaluation Index of Classification Algorithm. The precision rate can be used to measure the ratio of the number of correctly classified positive samples to the number of all positive samples in the sample, and the recall rate is used to measure the ratio of the number of wrongly classified positive samples to all positive samples. Let the correctly classified set be $\mathrm{A}$ and the wrongly classified set be $B$ :

$$
\begin{aligned}
\operatorname{Precision}(A, B) & =\frac{|A \cap B|}{|A|}, \\
\operatorname{Recall}(A, B) & =\frac{|A \cap B|}{|B|} .
\end{aligned}
$$

Coverage refers to the proportion of the number of samples we selected in the sample pool.

$$
\text { Accuracy }=\frac{1}{n} \sum_{i=1}^{n} 1\left(\hat{y}_{t}=y_{t}\right) \text {. }
$$

Support is a measure of how often $A B$ occurs at the same time.

$$
\begin{aligned}
& \text { Support }(A \longrightarrow B)=P(A \cup B), \\
& \text { Confidence }(A \longrightarrow B)=P(B \mid A), \\
& F 1=\frac{2 \times \text { precision } \times \text { recall }}{\text { precision }+ \text { recall }}
\end{aligned}
$$

\subsection{Art Culture Communication Experiment}

3.2.1. Research Content. This article designs an experiment on the art and culture of oil painting. The subjects of the experiment were randomly selected art students from $\mathrm{Y}$ University. The cultural dissemination methods, the original drawbacks of oil painting art and culture dissemination, and the effects of oil painting art culture dissemination are mainly researched.

3.2.2. Research Methods. This article mainly uses literature research method and questionnaire survey method. The theoretical basis of this research is discussed through the literature research method; the questionnaire survey method is used to explain the current situation of the spread of oil painting culture and so forth and summarize and analyze to form an effective way for the spread of oil painting art culture. The questions in the questionnaire survey dealt with basic information about the respondents and their knowledge of oil painting. 200 questionnaires were distributed and 154 were returned.

3.2.3. Data Analysis. This article analyzes the experimental process, highlights the effective application of communication technology, and improves the difficulties in the application of communication technology. 


\section{Research and Analysis Based on Mobile Information System and Oil Painting Art Appreciation Platform}

4.1. The Current Research Status of Art and Culture Communication in China. In order to understand the current research status of art and culture communication in our country and analyze the current status of different technology communication, this article selects 2008 to 2018 as the time limit, selects "cultural communication" as the search term, selects "oil painting art" as the search topic, and retrieves the full-text database and excellent paper database of Chinese journals. The search results show that there are a total of domestic publications. There were 1894 theses published, including 1323 theses, 46 doctoral theses, and 252 master's theses. As shown in Table 1 and Figure 1, this article compares the publication year of books and periodicals and the number of documents to form the distribution of the literature on oil painting art and culture communication [26].

4.2. Output Value and Scale of Oil Painting Art. It can be seen from Table 2 and Figure 2 that, in the analysis of the classification of the field of oil painting art, the total output value and added value of contemporary oil painting and oil painting materials are the largest, 85.63 billion yuan and 27.68 billion yuan, accounting for $65.8 \%$ and $50.3 \%$, respectively. The total output value and added value of figure painting and landscape painting were 22.92 billion yuan and 14.98 billion yuan, accounting for $33.4 \%$ and $49.2 \%$, respectively. This shows that the overall scale of my country's oil painting industry is expanding year by year, and its position in the national economy is also steadily improving.

4.3. Comparison of Consensus Mechanisms. The blockchain consensus mechanism is the soul of the blockchain system, and it is constructed by relying on the consensus algorithm in the distributed system. The workload proof mechanism is fundamentally different from the distributed consensus algorithm based on the replication state machine theory. The work in this paper analyzes and compares the characteristics of the two in detail. The proof-of-work mechanism will cause a lot of useless calculations, and the throughput and latency of its applications will therefore perform poorly.

The macro comparison of the two consensus mechanisms is shown in Table 3. For two different consensus mechanisms, they have different applicable scenarios. For example, in an anonymous network environment, we cannot know user information, nor can we perform node IP statistics. At this time, the workload proof method has avoided the unknowingness of node management and system environment. This allows the system to maintain consistency under the conditions of anonymity and being not fully connected.

Table 4 and Figure 3 show the TPS statistical results every ten seconds. We can see that as the number of nodes increases, the warm-up time becomes longer. The warm-up time of 4 nodes is not much different from the subsequent steady state, but when the number of nodes increases to 16 , it enters a relatively stable throughput state in about $90 \mathrm{sec}-$ onds. After the scale increases, the broadcast block traffic of the leader node becomes larger, the number of connected nodes increases, and the waiting time for a reply becomes longer. In the warm-up phase, the instantaneous TPS will first decrease and then gradually increase. As the number of test nodes increases, the decline becomes more pronounced and the rise process is longer.

4.4. The Spread of Oil Painting Art Culture. It can be seen from Table 5 and Figure 4 that the importance of cultural communication is different in the eyes of college students of different grades. Generally speaking, freshman students do not have a deep understanding of the concept of cultural communication, so there are more people who think that they are not important or indifferent in the interview data; students in the third and fourth grades are more concerned about cultural communication. The understanding is relatively deep, so the people who think that it is generally important and very important account for a relatively high proportion, reaching $42.8 \%$. In general, regarding cultural communication, schools should also deepen the theoretical courses on cultural communication, so that students can fully understand the importance of cultural communication, and, at the same time, they should continue to develop new cultural communication methods to inculcate students' cultural communication and exchanges.

The dissemination audiences of the western cultural circle mainly include the people of the United States, Britain, France, Germany, and Canada with advanced material civilization and high confidence in spiritual civilization. It can be seen from Table 6 and Figure 5 that, in 5 years, China's total output of oil painting art and cultural works to the United States was 3,987, occupying the first place; the United Kingdom ranked second with 2,226; Germany, France, and Canada were 1,879, 834, and 623 species, respectively. It can be seen that, even within the same cultural circles, the different countries have large differences in the number of Chinese oil paintings introduced. The introduction of Chinese oil paintings in the western cultural circle is uncertain and the stability is poor. It can be seen that Chinese oil painting culture is facing greater pressure to enter the western cultural circle.

The East Asian cultural circle is represented by China, Japan, South Korea, and Singapore. These countries have a high similarity to Chinese culture and have deep historical and realistic origins. It can be seen from Table 7 and Figure 6 that, from 2015 to 2019, the total output of China's oil paintings to South Korea was 3,033, occupying the first place, followed by Japan and Singapore with 1,730 and 1,438, respectively. In the past five years, the East Asian cultural circle introduced a total of 6201 kinds of Chinese oil paintings. In 2015, the number of oil paintings introduced was 1166. In the two following years, the number of imported oil paintings decreased slightly; from 2017 to 2019, the number of exported oil paintings increased from 1071 to 1597 types. 
TABLE 1: Literature quantity of intercultural communicative competence from 2008 to 2018.

\begin{tabular}{lcc}
\hline Years & Number of related literature & Growth ratio \\
\hline 2008 & 53 & - \\
2009 & 97 & 45.36 \\
2010 & 98 & 1.32 \\
2011 & 143 & 31.46 \\
2012 & 173 & 17.34 \\
2013 & 178 & 2.80 \\
2014 & 217 & 17.97 \\
2015 & 215 & -0.93 \\
2016 & 245 & 12.24 \\
2017 & 235 & -4.25 \\
2018 & 267 & 11.98 \\
\hline
\end{tabular}

Literature quantity of intercultural communicative competence

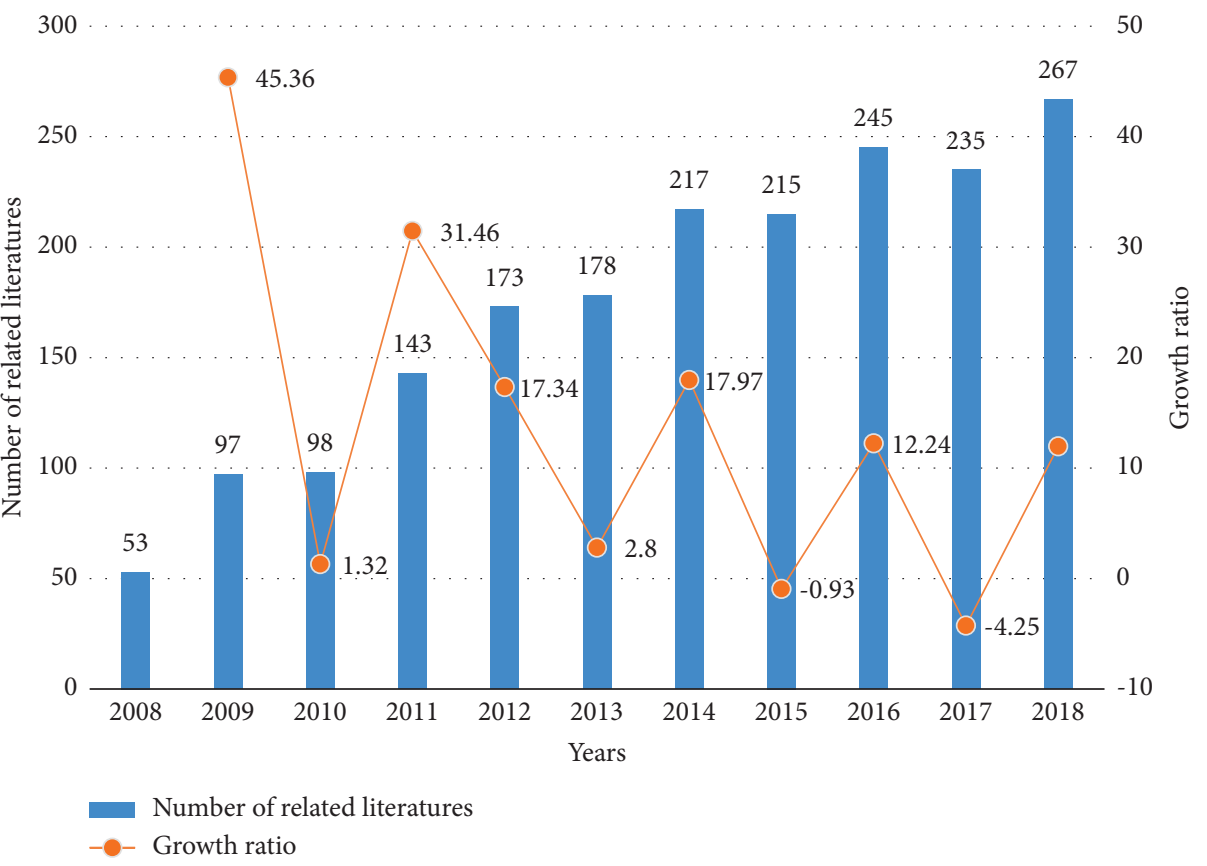

FIGURE 1: Literature quantity of intercultural communicative competence from 2008 to 2018.

TABLE 2: Total output value and added value of 11 categories of oil painting art in 2018 .

\begin{tabular}{lcccc}
\hline Oil painting art classification & Total output & Value added & Structure total output & Value added \\
\hline Openwork & 276.8 & 129.4 & 1.7 & 2.5 \\
Oil painting material & 856.3 & 458.3 & 0.4 & 8.3 \\
Oil painting tools & 47.2 & 14.5 & 1.5 & 0.3 \\
Oil painting on the shelf & 247.7 & 191.8 & 0.7 & 3.5 \\
Ancient oil painting & 100.1 & 40.8 & 0.9 & 0.7 \\
Modern oil painting & 149.8 & 52.6 & 1.7 & 1.1 \\
Contemporary oil painting & 276.8 & 129.4 & .5 \\
\hline
\end{tabular}




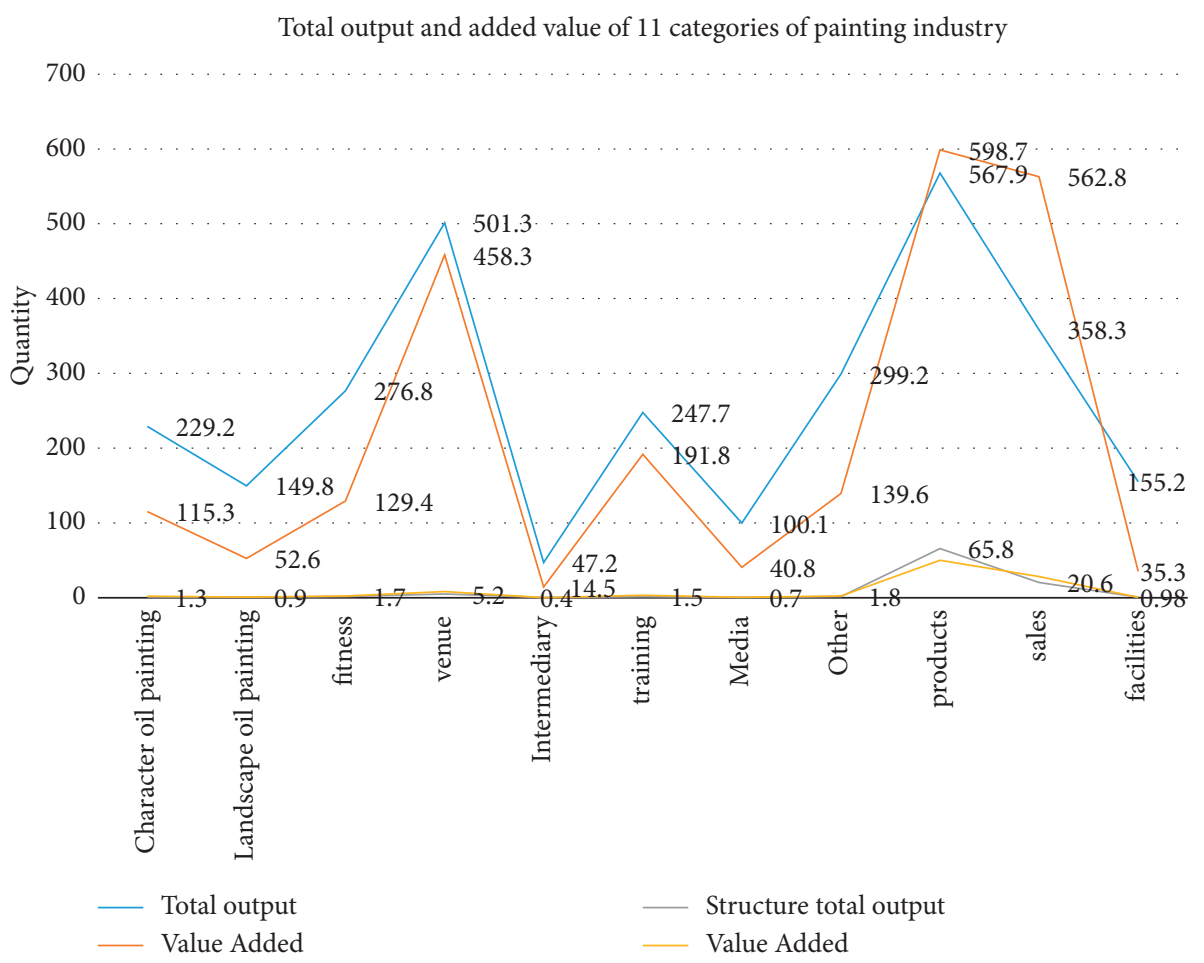

Figure 2: The total output value and added value of the 11 types of oil painting industry across the country.

TABLE 3: A macro comparison between the proof-of-work mechanism and the consensus algorithm based on the replication state machine theory.

\begin{tabular}{|c|c|c|c|c|c|c|}
\hline & $\begin{array}{l}\text { Node management } \\
\text { mechanism }\end{array}$ & Throughput & $\begin{array}{l}\text { Consensus is } \\
\text { a foregone } \\
\text { conclusion }\end{array}$ & Delay & Scalability & $\begin{array}{c}\text { Energy } \\
\text { consumption }\end{array}$ \\
\hline $\begin{array}{l}\text { Proof-of-work } \\
\text { mechanism }\end{array}$ & $\begin{array}{l}\text { None, any node can } \\
\text { join and exit at will }\end{array}$ & $\begin{array}{l}\text { Poor, affected by } \\
\text { possible fork }\end{array}$ & None & $\begin{array}{l}\text { High latency, } \\
\text { requiring multiple } \\
\text { blocks to wait for } \\
\text { confirmation }\end{array}$ & $\begin{array}{l}\text { Good, system } \\
\text { capacity and } \\
\text { availability are not } \\
\text { limited by the } \\
\text { number of nodes }\end{array}$ & $\begin{array}{l}\text { High, a lot of } \\
\text { useless calculations, } \\
\text { waste a lot of power } \\
\text { and other resources }\end{array}$ \\
\hline $\begin{array}{l}\text { Consensus } \\
\text { algorithm based } \\
\text { on replication } \\
\text { state machine }\end{array}$ & $\begin{array}{l}\text { Yes, permission is } \\
\text { required to enter. } \\
\text { Nodes in the system } \\
\text { virtually know the IP of } \\
\text { all nodes in the system }\end{array}$ & $\begin{array}{l}\text { High, can have a } \\
\text { throughput full } \\
\text { of network } \\
\text { capacity }\end{array}$ & Have & $\begin{array}{l}\text { Low latency, } \\
\text { related to network } \\
\text { latency }\end{array}$ & $\begin{array}{c}\text { Poor, system } \\
\text { availability } \\
\text { decreases as the } \\
\text { number of nodes } \\
\text { increases }\end{array}$ & $\begin{array}{c}\text { Low, no } \\
\text { complicated } \\
\text { calculation process }\end{array}$ \\
\hline
\end{tabular}

TABLE 4: Instantaneous throughput.

\begin{tabular}{lcccc}
\hline Time & 4 nodes & 8 nodes & 12 nodes & 16 nodes \\
\hline 10 & 7.12 & 5.28 & 3.89 & 3.28 \\
20 & 7.59 & 4.69 & 3.02 & 2.79 \\
30 & 7.66 & 4.78 & 3.12 & 1.03 \\
40 & 7.32 & 5.33 & 3.16 & 1.34 \\
50 & 7.34 & 7.22 & 3.18 & 1.28 \\
60 & 7.59 & 7.46 & 3.69 & 5.65 \\
70 & 7.46 & 7.32 & 6.98 & 6.12 \\
80 & 7.22 & 7.11 & 6.66 & 7.03 \\
90 & 7.13 & 7.02 & 6.25 & 6.59 \\
100 & 7.22 & 7.09 & 6.28 & 6.62 \\
110 & 7.25 & 7.38 & 6.59 & 6.89 \\
120 & 7.26 & 7.12 & 6.38 & \\
\hline
\end{tabular}


TABLE 4: Continued.

\begin{tabular}{lcccc}
\hline Time & 4 nodes & 8 nodes & 12 nodes & 16 nodes \\
\hline 130 & 7.17 & 7.16 & 6.49 & 6.52 \\
140 & 7.14 & 7.03 & 6.55 & 6.34 \\
150 & 7.22 & 7.05 & 6.49 & 6.58 \\
160 & 7.23 & 7.16 & 6.59 & 6.22 \\
170 & 7.15 & 7.12 & 6.89 & 6.59 \\
180 & 7.16 & 7.13 & 6.77 & 6.68 \\
190 & 7.22 & 7.15 & 6.34 \\
\hline
\end{tabular}

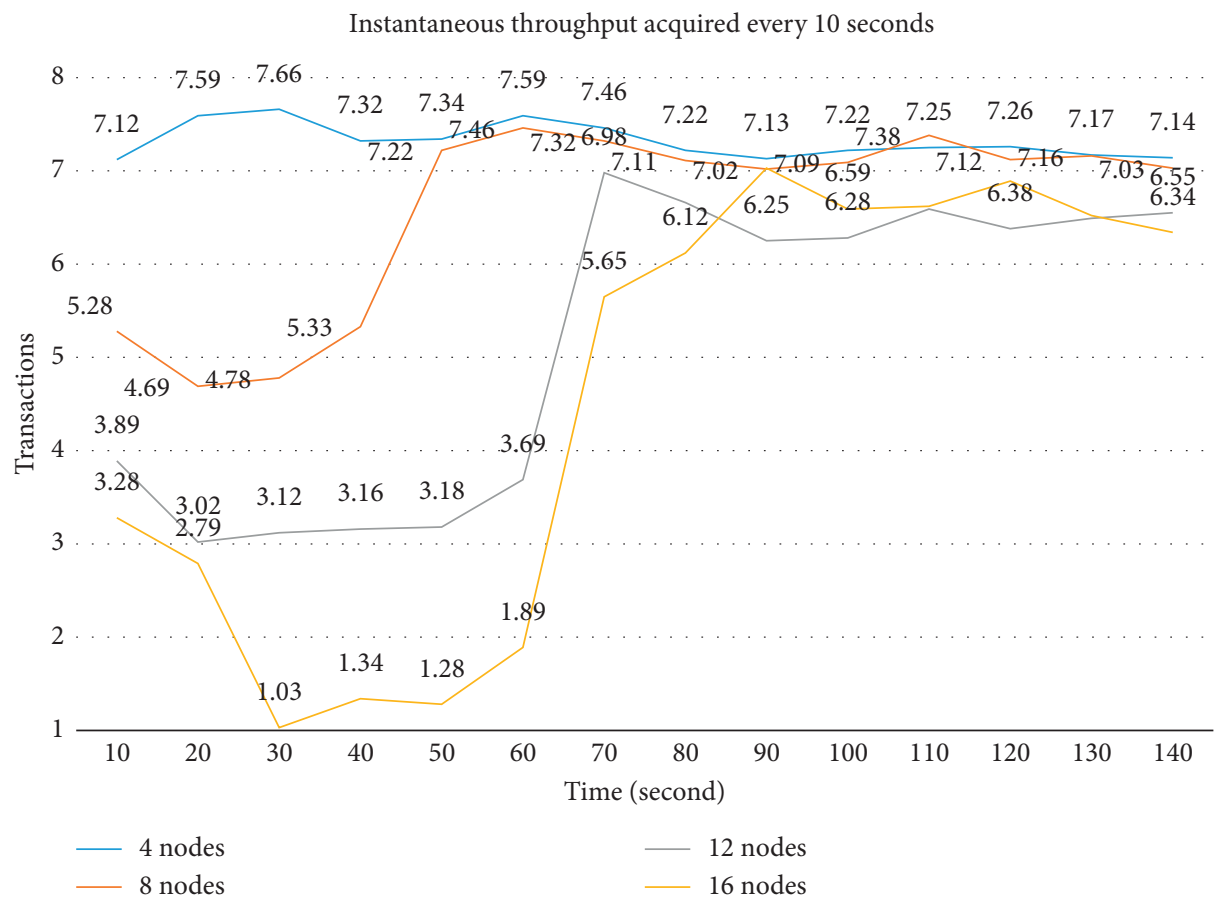

Figure 3: Instantaneous throughput.

TABLE 5: The importance of cultural communication.

\begin{tabular}{lcccc}
\hline Interview crowd & Unimportant & It does not matter & Generally important & Very important \\
\hline Freshman & 38.4 & 22.5 & 16.7 & 15.8 \\
Sophomore & 26.5 & 27.8 & 22.8 & 29.7 \\
Junior & 12.7 & 8.9 & 38.8 & 36.9 \\
Senior year & 8.6 & 9.8 & 36.7 & 42.8 \\
\hline
\end{tabular}




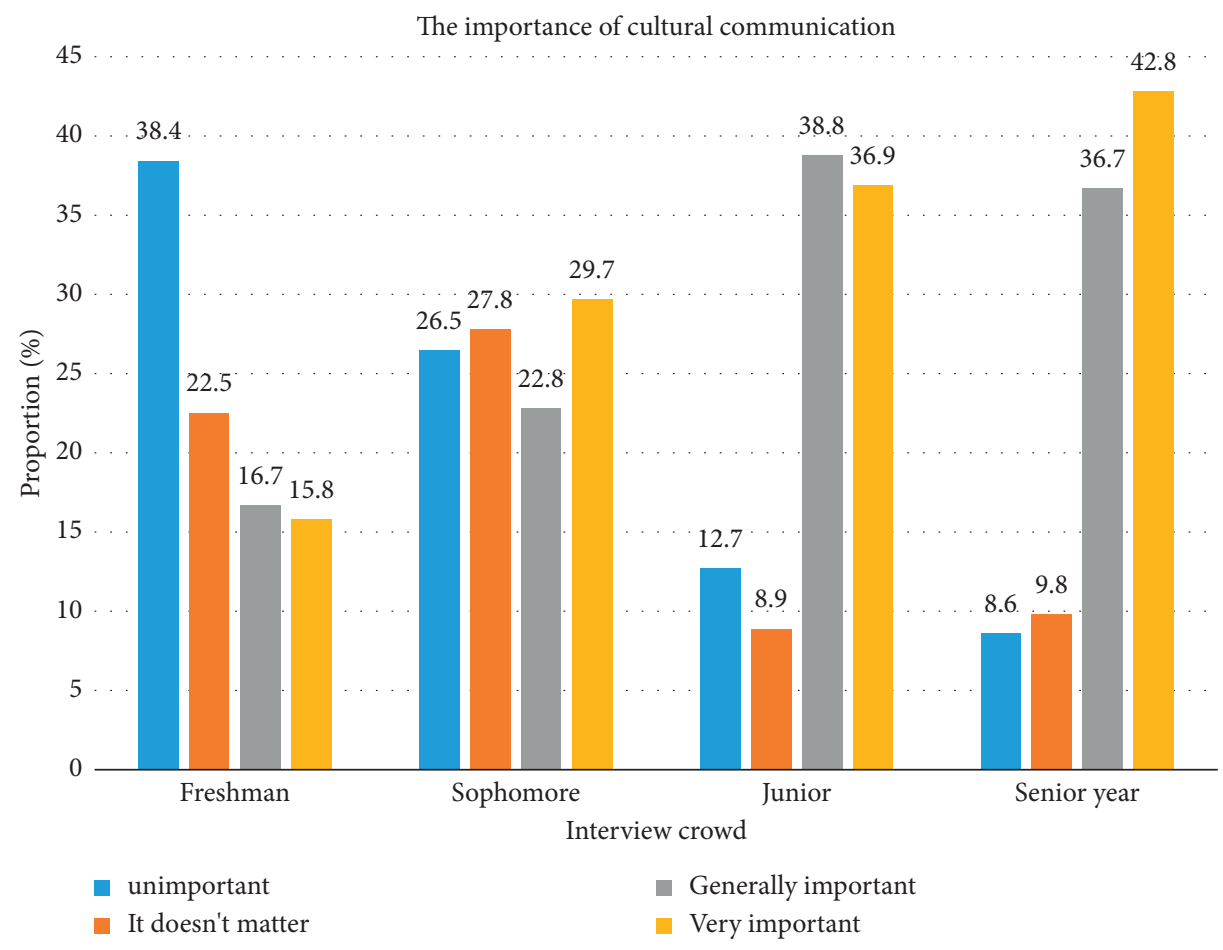

FIGURE 4: The importance of cultural communication.

TABLE 6: Analysis of the total output of oil painting culture from 2015 to 2019 (species).

\begin{tabular}{lcccccc}
\hline Years & 2015 & 2016 & 2017 & 2018 & 2019 & Sum \\
\hline United States & 856 & 933 & 594 & 911 & 488 & 612 \\
United Kingdom & 556 & 291 & 423 & 422 & 436 & 495 \\
Germany & 381 & 263 & 189 & 255 & 391 & 2227 \\
France & 134 & 115 & 224 & 113 & 181 \\
Canada & 82 & 86 & 1829 & 2180 & 132 & 1789 \\
Sum & 2034 & 1682 & & 644 \\
\end{tabular}

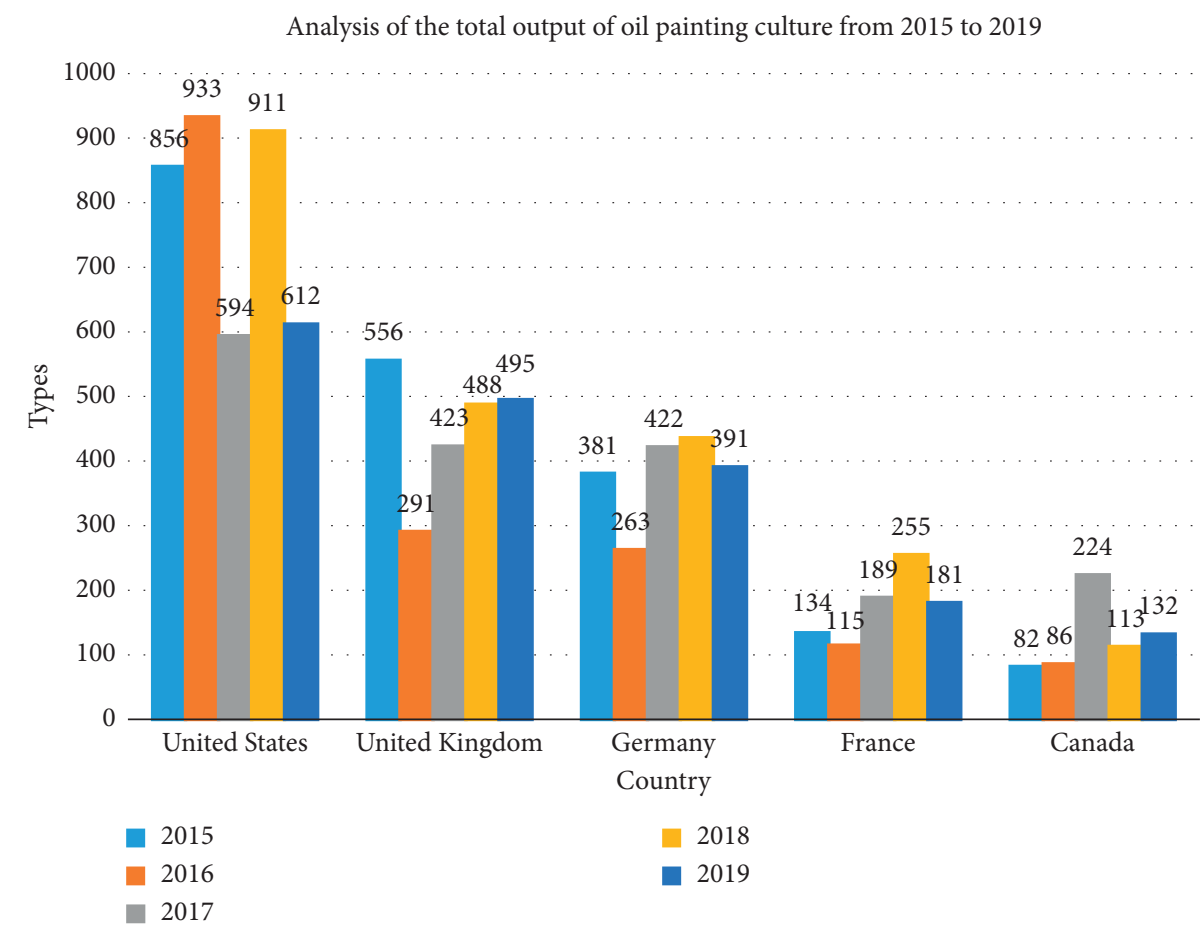

FIGURE 5: Analysis of the total output of oil painting culture from 2015 to 2019. 
TABLE 7: China's total output of oil painting culture in the East Asian cultural circle (2015-2019).

\begin{tabular}{lcccccc}
\hline Years & 2015 & 2016 & 2017 & 2018 & 2019 & \\
\hline Singapore & 263 & 188 & 152 & 338 & 414 & 1439 \\
Japan & 275 & 354 & 338 & 418 & 369 & 1731 \\
Korea & 629 & 556 & 481 & 522 & 303 \\
Sum & 1167 & 1113 & 1071 & 1255 & 1598 & 3034 \\
\hline
\end{tabular}

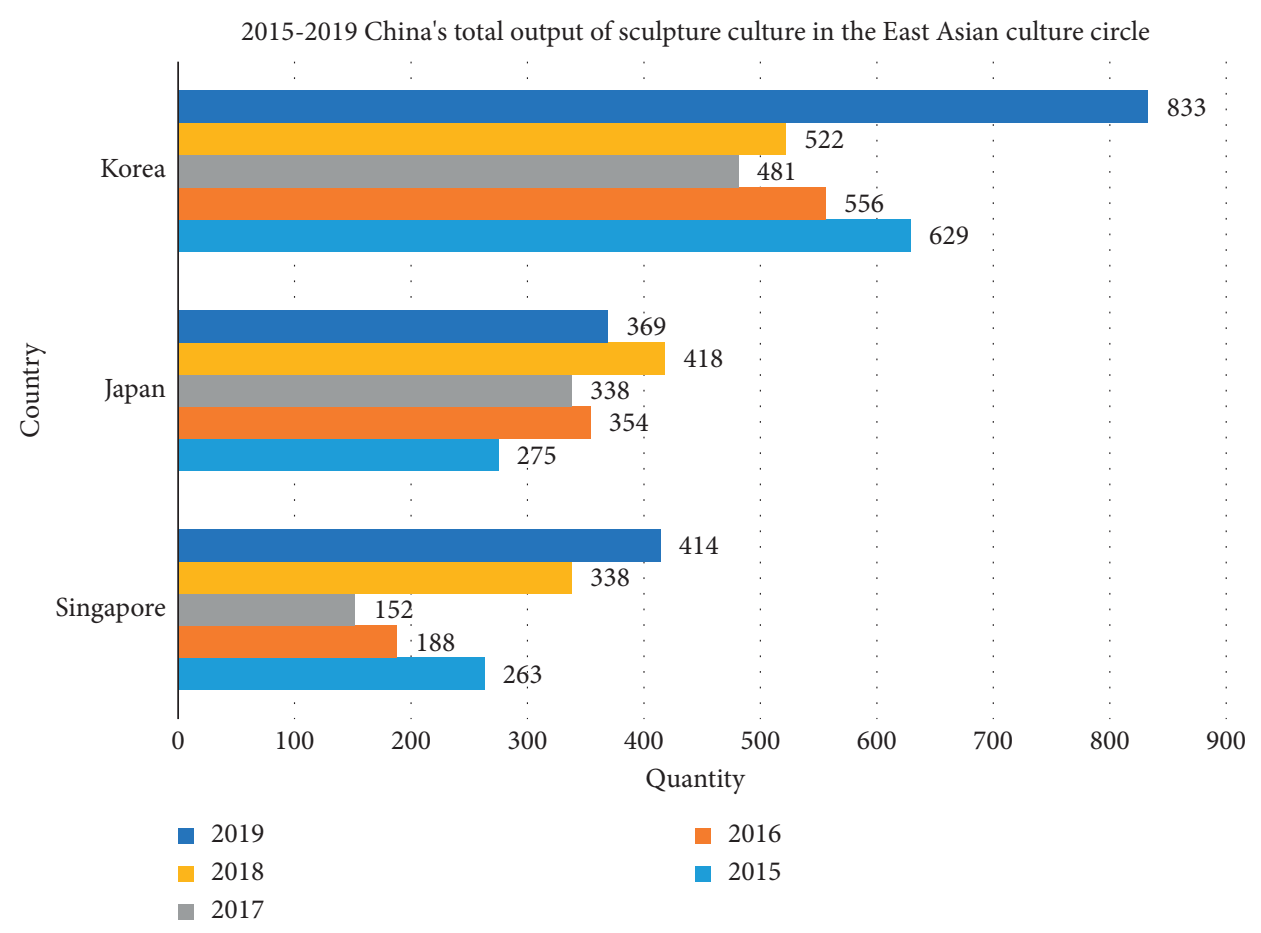

FIgURE 6: China's total output of oil painting culture in the East Asian cultural circle (2015-2019).

\section{Conclusion}

This article is mainly to study the cultural dissemination of oil painting art based on mobile information systems. The development of digital technology brings the possibility of solving cultural dissemination to oil painting culture. In addition, oil painting art should also seize the opportunity of the times to expand its influence, spread its own excellent culture, and promote social development and progress. This article studies the courage to break the traditional forms of art and culture dissemination and proposes new forms of promoting cultural dissemination from the perspective of high-tech in the new era to expand cultural exchanges. This article still has some shortcomings, such as the fact that the research data is not comprehensive enough.

\section{Data Availability}

No data were used to support this study.

\section{Conflicts of Interest}

The author declares that there are no conflicts of interest regarding the publication of this article.

\section{Acknowledgments}

This work was supported by Inner Mongolia Autonomous Region Educational Science "Thirteenth Five-Year" Project (Project Name: Inheritance and Innovation of Three Special Minority Cultures in Underdeveloped Northern Areas in College Art Design Teaching).

\section{References}

[1] J. J. Sikorski, J. Haughton, and M. Kraft, "Blockchain technology in the chemical industry: machine-to-machine electricity market," Applied Energy, vol. 195, pp. 234-246, 2017.

[2] G. Gao, "Psychology of cross cultural communication: an impact on the health care system," Journal of Biological Regulators and Homeostatic Agents, vol. 32, no. 5, pp. 12111214, 2018.

[3] A. Hotsaliuk, "Art of sculpture and its development in Ukraine (late 20th-early 21st century)," Ukrainian Studies, vol. 1, no. 70, pp. 67-75, 2019.

[4] Y. Zhang and J. Wen, "The IoT electric business model: using blockchain technology for the internet of things," Peer-to-Peer Networking and Applications, vol. 10, no. 4, pp. 983-994, 2017.

[5] P. Yeoh, "Regulatory issues in blockchain technology," Journal of Financial Regulation and Compliance, vol. 25, no. 2, pp. 196-208, 2017. 
[6] M. H. Miraz and M. Ali, "Applications of blockchain technology beyond cryptocurrency," Annals of Emerging Technologies in Computing, vol. 2, no. 1, pp. 1-6, 2018.

[7] J. Sun, J. Yan, and K. Z. K. Zhang, "Blockchain-based sharing services: what blockchain technology can contribute to smart cities," Financial Innovation, vol. 2, no. 1, pp. 1-9, 2016.

[8] R. Beck, M. Avital, M. Rossi, and J. B. Thatcher, "Blockchain technology in business and information systems research," Business \& Information Systems Engineering, vol. 59, no. 6, pp. 381-384, 2017.

[9] M. A. Engelhardt, "Hitching healthcare to the chain: an introduction to blockchain technology in the healthcare sector," Technology Innovation Management Review, vol. 7, no. 10, pp. 22-34, 2017.

[10] Y. Yuan, T. Zhou, A. Y. Zhou et al., "Blockchain technology: from data intelligence to knowledge automation," Zidonghua Xuebao/Acta Automatica Sinica, vol. 43, no. 9, pp. 1485-1490, 2017.

[11] M. O'Dair and Z. Beaven, "The networked record industry: how blockchain technology could transform the record industry," Strategic Change, vol. 26, no. 5, pp. 471-480, 2017.

[12] G. Gabisori, "Policy considerations for the blockchain technology public and private applications," SMU science and technology law review, vol. 19, no. 3, pp. 327-350, 2016.

[13] S. Mansfield-Devine, "Beyond Bitcoin: using blockchain technology to provide assurance in the commercial world," Computer Fraud \& Security, vol. 2017, no. 5, pp. 14-18, 2017.

[14] A. Prashanth Joshi, M. Han, M. Han, and Y. Wang, "A survey on security and privacy issues of blockchain technology," Mathematical Foundations of Computing, vol. 1, no. 2, pp. 121-147, 2018.

[15] M. Buitenhek, "Understanding and applying Blockchain technology in banking: evolution or revolution?" Journal of Digital Banking, vol. 1, no. 2, pp. 111-119, 2016.

[16] T. Y. Chao, "Russia/Russians on ice: imagined identity and cross-cultural communication in yuri!!! ICE," Interface --Journal of European Languages and Literatures, vol. 9, pp. 59-87, 2019.

[17] B. G. M. Hawali and D. Cyrielle, "Review of mass media effect in inter-cultural communication," International Journal of Communication and Society, vol. 2, no. 2, pp. 94-101, 2020.

[18] Rahmadianawati, Z. A. Makam, Z. Ar, Oknita, and S. Mahdi, "Covid handling in aceh; cultural communication perspective," Asian Social Science and Humanities Research Journal (ASHREJ), vol. 2, no. 2, pp. 28-36, 2020.

[19] M. Khalil, "Features of the Russian-Egyptian cross-cultural communication: business and management dimensions," RUDN Journal of World History, vol. 11, no. 1, pp. 56-64, 2019.

[20] V. Kovalenko, "A literary text as a mediator in inter-cultural communication," Humanities science current issues, vol. 1, no. 21, pp. 172-175, 2019.

[21] Voss-Andreae and Julian, "Quantum sculpture: art inspired by the deeper nature of reality," Leonardo, vol. 44, no. 1 , pp. 14-20, 2017.

[22] M. Samsun, "The issue of "space" in the art of sculpture," Idil Journal of Art and Language, vol. 6, no. 32, pp. 1283-1298, 2017.

[23] P. Ward-Jackson, "Sculpture victorious. Art in an age of invention, 1837-1901," Sculpture Journal, vol. 25, no. 2, pp. 285-287, 2016.

[24] D. D. Utami and F. Nurfitri, "Pengaruh electronic word of mouth terhadap travel intention wisatawan ke nuart sculpture park bandung," Jupiis Jurnal Pendidikan Ilmu-Ilmu Sosial, vol. 12, no. 2, pp. 424-429, 2020.

[25] R. C. Ferrari, "The modernity of ancient sculpture: Greek sculpture and modern art from Winckelmann to Picasso, Prettejohn Elizabeth, London; New York: I. B. Tauris, 2012. 320 p. ill. ISBN 9781848859029. u00a357.50/\$95.00 (hardcover)," Art Libraries Journal, vol. 38, no. 4, pp. 320-361, 2016.

[26] D. Zhang and C. Xia, "Ice and snow sports education based on $5 \mathrm{G}$ cloud computing to improve the social adaptability of southern university students," Scientific Programming, vol. 2021, Article ID 3828624, 12 pages, 2021. 